\title{
Design and Research of Marine Non-thermal Plasma Reactor
}

\author{
Lei Jiang ${ }^{1,2, a}$, Wei Sun ${ }^{3, b}$ \\ ${ }^{1}$ School of Energy and Power Engineering, Jiangsu University of Science and Technology, \\ Zhenjiang, Jiangsu 212003, China \\ ${ }^{2}$ School of Automotive and Traffic Engineering, Jiangsu University, Zhenjiang, Jiangsu, 212013, \\ China \\ ${ }^{3}$ Shanghai Odely Marine Engineering Co., Ltd, Shanghai, 200023, China, \\ a jiang974212@163.com, bdavidsun@odely.com
}

Keywords: gas treatment, non-thermal Plasma, marine Diesel

Abstract. This paper introduces a new technology of exhaust treatment: dielectric barrier discharge plasma technology. Non-thermal plasma (NTP) has been studied as a potential candidate for diesel engine exhaust after-treatment, and the NTP reactor was the critical component in the technology. Research shows that, combined the NTP catalytic purification technology with the existing purification technology could overcome the shortcomings of existing catalyze, improve the efficiency of the engine exhaust particulate matter, hydrocarbons and nitrogen oxides, and has a wide application prospect.

\section{Introduction}

The high efficiency of the diesel engine has made it the primary propulsion source for marine applications worldwide [1].Plasma is called in addition to solid, liquid and gas outside of the fourth kind of existing material form. According to the particle temperature, Plasma can be divided into thermal Plasma and non-thermal Plasma (NTP) . Non-thermal plasma is mainly produced by gas discharge, discharge gas electronic temperature typically up to tens of kelvin, while the other particle temperature is $300 \sim 500 \mathrm{~K}$. Non-thermal plasma reactors can be used as a particulate trap or as a NOx converter. The effective oxidation of $\mathrm{NO}$ to $\mathrm{NO}_{2}$ is produced by active compounds, which are generated in plasma. Particulate trapping in a plasma reactor can be accomplished by electrostatic precipitation. The oxidation of the carbon fraction by $\mathrm{NO}_{2}$ can be used to decrease the concentration of particulate matter. The general gas discharge generation of plasma belongs to low temperature plasma. Diesel NOx after-treatment is a serious problem since the concentration of oxygen is a high value in exhaust gas. It may be more than 5 vol\% [2].

Dielectric barrier discharge (DBD) is one of non-thermal plasma techniques, and it offers the advantage to excite molecules for reaction processes on a low temperature level in the near-atmospheric pressure range [3]. NOx is reduced at low temperature when $\mathrm{NO}_{2}$ is involved in the reaction mechanism. Therefore, if non-thermal plasma converts $\mathrm{NO}$ to $\mathrm{NO}_{2}$, the reduction rate of NOx will be greatly enhanced in the catalytic process even at a low temperature.

\section{Research Actuality}

In the $1990 \mathrm{~s}$, foreign began to research use the low temperature plasma technology to reduce the diesel exhaust [4-18].Using the low NTP technology research and development of automobile 
exhaust purification device besides general automobile exhaust purifier has the function of, still have the following features:

1) Reduce the engine's fuel consumption.

2) Reduce the engine's noise, smooth operation.

3) Improve the engine's starting acceleration.

4) Under the bad environment, ignition start-up success rate of $100 \%$.

5) Lower organic matter in the tail gas and emissions of carbon monoxide and other noxious substance.

6) It's applicable to any type of fuel engine, generator.

\section{The design principles of Marine diesel engine after-treatment system}

Compared with the traditional emission after-treatment device, Marine diesel engine's working environment is complicated, should have the following features:

1) The Marine diesel engine's exhaust gas temperature and flow rate are higher than ordinary diesel engine.

2) Compared with the ordinary diesel engine, Marine diesel engine's exhaust gas in the PM concentration is higher.

3) The complex working conditions when the ship sailing, mechanical vibration strength.

4) The working space is limited, diesel engine layout is compact.

So in the design of non-thermal plasma purification system from the following factors must be considered:

1) After adding after-treatment system, does not affect the Marine diesel engine performance and fuel economy, should have a lower exhaust back pressure and flow resistance.

2) Equipped with after-treatment system, exhaust reached the international maritime organization (IMO) standard of T3.

3) After-treatment system should be used in high quality catalyst.

4) It can be used in the navigation of ships under the various working conditions.

5) After-treatment system should have low cost, small volume, long service life, etc.

\section{The design of the NTP reactor}

The design of diesel engine selection Volvo D7ATA diesel engine co., LTD., production, installed in 23 meters tourist ship. This ship is a single engine and propeller oblique direct drive, its main technical parameters as shown in table 1:

\begin{tabular}{|l|l|l|l|}
\hline \multicolumn{4}{|c|}{ Model: D7ATA } \\
\hline $\begin{array}{l}\text { The cylinder } \\
\text { diameter }\end{array}$ & $108 \mathrm{~mm}$ & Piston stroke & $130 \mathrm{~mm}$ \\
\hline Rated power & $130 \mathrm{KW}$ & Compression ratio & 18 \\
\hline Rated speed & $1500 \mathrm{rpm}$ & $\begin{array}{l}\text { Rated power } \\
\text { consumption }\end{array}$ & $217( \pm 5 \%) \mathrm{g} / \mathrm{kW} \cdot \mathrm{h}$ \\
\hline $\begin{array}{l}\text { The piston } \\
\text { emissions }\end{array}$ & $7.15 \mathrm{~L}$ & Cooling way & $\begin{array}{l}\text { Closed loop water } \\
\text { cooling }\end{array}$ \\
\hline
\end{tabular}

Table 1 D7ATA diesel engine main specifications and parameters 


\section{The design of the reactor inlet diameter}

Considering the design of Marine NTP reactor during diesel engine emissions and exhaust pipe size, when designing the entrance of the NTP reactor, we used the outlet size of the turbocharger directly. So that we can reduce the possibility of eddy current which will affect the power performance and fuel economy in the process of operation of the ship. After consulting the sightseeing boat found it's hull structure design drawing of the outlet of the turbocharger size is $72 \mathrm{~mm}$, so the entrance of the NTP reactor size is $72 \mathrm{~mm}$.

\section{The reactor volume}

Check the related information, the piston total emissions calculation formula is followed.

$$
V_{h}=\pi\left(\frac{D}{2}\right)^{2} h
$$

Where, $\mathrm{D}$ is the piston diameter, $\mathrm{mm} ; \mathrm{h}$ is the piston stroke, $\mathrm{mm}$. According to table 1 , there are:

$$
\begin{aligned}
& V_{h}=\pi\left(\frac{D}{2}\right)^{2} h=\pi \times\left(\frac{1.08}{2}\right)^{2} \times 1.3 \times 6 \\
& V_{h}=7.15 L
\end{aligned}
$$

The NTP reactor design mainly depends on the volume of the diesel engine emissions.If the volume design is reasonable, not only can improve the purification efficiency and reduce power loss, also can increase the life of the reactor.This design in calculating volume formula references available:

$$
V=\frac{K V_{s} i}{n} \sqrt{\frac{1}{Z}}
$$

Where, $\mathrm{K}$ is constant, the value range is 5000 to 50000 , according to the actual situation values; Vs is the engine displacement, $\mathrm{L}$; $\mathrm{i}$ is coefficient, 4 stroke diesel engine $\mathrm{i}=1,2$ stroke diesel engines $\mathrm{i}=$ $2 ; \mathrm{n}$ is the calibration speed, $\mathrm{RPM} ; \mathrm{Z}$ is the diesel engine cylinder number.There are:

$$
\begin{aligned}
& V=\frac{K V s i}{n} \sqrt{\frac{1}{Z}} \\
& V=\frac{7.15 \times 4 \times 15000 \times 6}{1500} \times \sqrt{\frac{1}{6}} \\
& V=700 L
\end{aligned}
$$

\section{The reactor size design}

Determine the diameter of the reasonable NTP reactor, not only can improve the efficiency of exhaust gas purification can also reduce the power loss. Meanwhile, we can estimate the length and diameter of the reactor according to the empirical formula.

$$
\begin{aligned}
V & =\frac{1}{4} \pi D^{2} \\
L & =2 D
\end{aligned}
$$

Where, L is the length of the NTP reactor, $\mathrm{mm}$; D is the NTP reactor diameter, $\mathrm{mm}$.

$$
D=299 \mathrm{~mm} \quad L=598 \mathrm{~mm}
$$




\section{The design of the reactor outlet diameter}

$$
S_{1}=K_{1} \bullet K_{2} \bullet V s
$$

Where, $\mathrm{S}_{1}$ is the reactor inlet area, $\mathrm{cm}^{2} ; \mathrm{K}_{1}$ is the correction coefficient, 4 stroke is $0.01,2$ stroke is $0.02 ; \mathrm{K}_{2}$ is the speed correction coefficient, $\mathrm{K}_{2}=0.7+10^{-4} \mathrm{n}, \mathrm{n}$ is the rated speed,rpm; $\mathrm{V}_{\mathrm{s}}$ is the engine emission, $\mathrm{ml}$.

In general, the reactor inlet diameter is larger than the diameter of a vent. With the formulas given above are:

$$
\begin{aligned}
& S_{2}=K_{1} \bullet K_{2} \bullet V_{s} \\
& S_{2}=0.01 \times\left(0.7+10^{-4} \times 1500\right) \times 715 \times 6 \\
& S_{2}=36.5
\end{aligned}
$$

Where, $S_{2}$ is the reactor outlet area, $\mathrm{cm} 2 ; \mathrm{D}_{2}=68 \mathrm{~mm}, \mathrm{D}_{2}$ is the reactor outlet diameter.

\section{Determine the diameter of the discharge electrode}

In under the action of high frequency high voltage plus, DBD units with low temperature plasma discharge area, when the exhaust through the area, exhaust and high-energy reactive molecules will happen, in the material REDOX reaction. A reasonable applied voltage can make cleaning more fully, so through access to relevant data using high frequency power supply is used as the reactor supporting power.At the same time, the discharge of dielectric barrier discharge unit in the general case $25 \mathrm{~mm}$ chosen as the diameter, discharge gap is $4 \mathrm{~mm}$.

\section{Schematic diagram of the reactor}

Fig. 1 is the Schematic diagram of the reactor. Throughout the schematic, inlet diameter of $72 \mathrm{~mm}$, and the same size on the ship exports of the turbocharger. Reactor's material is stainless steel, the reactor shape is a length of $598 \mathrm{~mm}$, outside diameter is $299 \mathrm{~mm}$ cylindrical steel tube. Inside the reactor into 25 groups of dielectric barrier discharge unit, a single unit discharge of outside diameter is $25 \mathrm{~mm}$, inner diameter of $20 \mathrm{~mm}$. The discharge unit of corundum tube material, length is 217 $\mathrm{mm}$. At the same time, when I design in the interior of the discharge unit placed a length of $159 \mathrm{~mm}$ is made of stainless steel inner electrode (high voltage electrode).

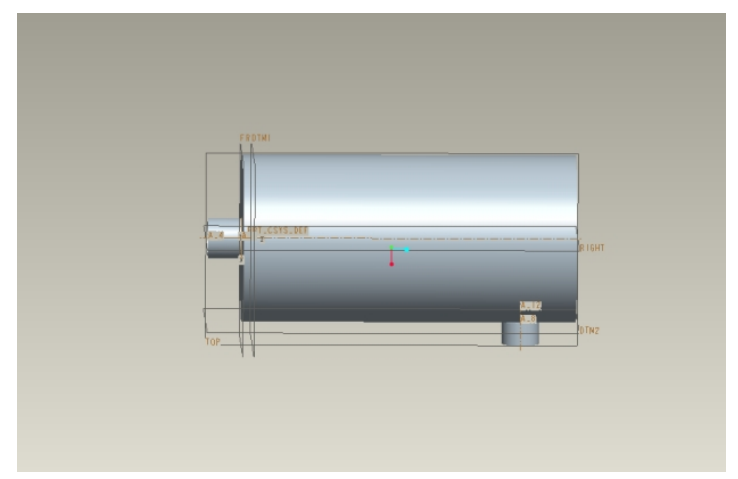

Fig.1 Schematic diagram of the reactor 


\section{Conclusions}

This article obtains from the diesel engine exhaust gas purification, the overall plan formulation, do the following work:

1) The non-thermal plasma technology is used to design a kind of Marine diesel exhaust gas after-treatment device to reduce diesel engine exhaust emissions.

2) Refer to the empirical formula in the literature, the design of the reactor size was determined by the calculation, the low temperature plasma purification device matching the appropriate power supply device, do the preliminary work for progress of a study.

\section{Acknowledgements}

This work was financially supported by the advantages of Jiangsu province college preponderant discipline (Naval Architecture and Marine Engineering) and Doctoral student innovation fund in jiangsu province in 2013.

\section{References}

[1] W. Müller, H. Ölschlegel, A. Schäfer, N. Hakim and K. Binder, 2003. Selective Catalytic Reduction-Europe's Nox Reduction Technology. Future Transportation Technology Conference, June 23-25, 2003, Costa Mesa, California.

[2] J.-O. Chae. Non-thermal plasma for diesel exhaust treatment. Journal of Electrostatics 57 (2003) 251-262.

[3] Y. H. Lee, J. W. Chung, Y. R. Choi, J. S. Chung, M. H. Cho,1 and W. Namkung. NOx Removal Characteristics in Plasma plus Catalyst Hybrid Process. Plasma Chemistry and Plasma Processing, Vol. 24, No. 2, June 2004:137-154.

[4] Shin, H. H., Yoon, W. S. Hydrocarbon Effects on the Promotion Non-Thermal Plasma NO-NO2 Conversion [J]. Plasma Chemistry and Plasma Processing, 2003, 23 (4): 681-704.

[5] Dsrinivasan, A., Rajanikanth, B. S. Nonthermal-Plasma-Promoted Catalysis for the Removal of NO $x$ from a Stationary Diesel-Engine Exhaust [J]. IEEE Transactions on Industry Applications, 2007, 43 (6): 1507-1514.

[6] Martin, A. R., Shawcross, J. T., Whitehead, J. C. Modelling of non-thermal plasma aftertreatment of exhaust gas streams [J]. Journal of Physics D: Applied Physics, 2004, 37 (1): 42-49.

[7] Gorce, O., Jurado, H., Thoma, C., Mariadassou, G. D. Non-Thermal Plasma Assisted Catalytic NOx Remediation from A Lean Model Exhaust [C]. SAE: 2001-01-3508.

[8] Srinivasan, A. D., Rajanikanth, B. S. Pulsed Plasma Treatment for NOx Reduction from Filtered/Unfiltered Stationary Diesel Engine Exhaust [J]. IEEE Transactions on Plasmas Science, 2007, 15 (2): 1893-1900.

[9] Gang, Y., Qi, Y., Z. K. S., Zhai X. D. Synergistic Removal of Nitrogen Monoxide by Non-Thermal Plasma and Catalyst Simultaneously [C]. Journal of Environmental Science, 2005, 17 (5): 846-848.

[10] Srinivasan, A. D., Rajanikanth, B. S. Non-thermal Plasma-Promoted Catalysis for the Removal of NOx from a Stationary Diesel-Engine Exhaust [J]. IEEE Transactions on Industry Application, 2007, 43 (6): 1507-1514.

[11] Orlandini, I., Riedel, U. Oxidation of propene and the formation of methyl nitrate in 
non-thermal plasma discharges [J]. Catalysis Today, 2004, 89 (1-2): 83-88.

[12]Hill, S. L., Kim, H. H., Futamura, S., Whitehead, J. c. The destruction of Atmospheric pressure propane and propene using a surface discharge plasma reactor [J]. The Journal of Physical Chemistry A, 2008, 112 (17): 3953-3958.

[13]Pasquiers, M., Postel, B., Magne, H., Puech, C. Lombardi, Study of Hydrocarbons Conversion in Air Using an Homogeneous Pre-ionised Discharge [J]. Journal of Advanced Oxidation Technology, 2004, 7 (2): 108-115.

[14]Jarrige, J., Vervisch, P. Decomposition of three volatile organic compounds by nanosecond pulsed corona discharge: Study of by-product formation and influence of high voltage pulse parameters [J]. Journal of Applied Physics, 2006, 99 (113303): 1-10.

[15]Chae, J. O. Non-thermal plasma for diesel exhaust treatment [J]. Journal of Electrostatics, 2003, 57 (3-4): 251-262.

[16]Lomnardi, G., Blin-Simiand, N., Jorand, F., Magne, L. Effect of propene, n-decane, and Tuluene plasma kinetics on NO conversion in homogeneous oxygen-rich dry mixtures at ambient temperature [J]. Plasma Chemistry and Plasma Processing, 2007, 27 (4): 414-445.

[17]Filimonova, E. A., Kim, Y. H., Hong, S. H., Song, Y. H. Multi-parametric investigation on NOx removal from simulated diesel exhaust with hydrocarbons by pulsed corona discharge [J]. Journal of physics D: Applied Physics, 2002, 35 (21): 2795-2807.

[18] Nie, Y., Wang, J. Y., Zhong, K., Wang, L. M., Guan, Z. C. Role of nitrogen-containing organic compound in plasma exhaust treatment [J]. Catalysis Communications, 2007, 8 (12): 2153-2158. 